\title{
An Exploration of Neighborhood Residents' Cognition of and Participation in Low-Carbon Behaviors in Wuhan, China
}

\author{
Wenjun Peng $\left(\mathbb{D},{ }^{1}\right.$ Xiaoming Wang, ${ }^{1}$ and Lijun Guo ${ }^{2}$ \\ ${ }^{1}$ School of Civil Engineering and Mechanics, Huazhong University of Science and Technology, Wuhan 430074, China \\ ${ }^{2}$ School of Environment Science and Engineering, Huazhong University of Science and Technology, Wuhan 430074, China \\ Correspondence should be addressed to Wenjun Peng; wenjun325@126.com
}

Received 8 November 2017; Accepted 12 March 2018; Published 5 April 2018

Academic Editor: Robert Černý

Copyright ( 2018 Wenjun Peng et al. This is an open access article distributed under the Creative Commons Attribution License, which permits unrestricted use, distribution, and reproduction in any medium, provided the original work is properly cited.

\begin{abstract}
This paper analyzed neighborhood residents' cognition of and participation in low-carbon behaviors, basing on a questionnaire survey launched in a neighborhood in Wuhan, China. Results indicate that most respondents concerned the low-carbon impact on their daily lives and expected the government to make differences in low-carbon transition. Neighborhood residents' participation in low-carbon behaviors was mainly reflected in three aspects: home energy conservation (HEC), efficient resource consumption (ERC), and recycling habits (RH), which were extracted from the five categories out of the 15 observed variables. Many interviewees had high level of participation in low-carbon behaviors that affect their economic interests. But these neighborhood residents rarely participated in public low-carbon behaviors such as planting trees or cooperative low-carbon behaviors. Therefore, these neighborhood residents' participation in low-carbon behaviors was still on the initial stage. Specific proposals were put forward to promote urban low-carbonization further.
\end{abstract}

\section{Introduction}

People are responsible for adopting policies and measures of mitigation and adaptation on global warming within the framework of sustainable development. The proposed concept of low-carbon economy is a significant step forward in the global fight against climate change. Cities in China are upgrading into a critical growth period [1], with low-density types of agricultural land continually transferring to highdensity types of urban land [2]. China's urbanization rate rapidly increased from $17.9 \%$ in 1978 at the beginning of reform and opening up to $56.10 \%$ in 2015 [3]. It is expected to reach $70 \%-75 \%$ in 2050 [4]. As sequential amplification of demand for natural resources and energy, cities have become the main entity of carbon emissions and are responsible for $85 \%$ of total national carbon emissions [5]. In the process of responding to global climate change, urban low-carbon transformation is an inevitable choice for the construction of ecological civilization and new pattern of urbanization [6]. Neighborhoods are basic units for the development and improvement of functional area filling with intensive human activities that play important roles in urban low-carbon transition. Residents who influence the size and shape evolution of neighborhoods are behavioral agents to fulfill the roles and create sustainable neighborhoods. Therefore, the research on neighborhood residents' cognition of and participation in low-carbon behaviors has great significance for the implementation of urban low-carbon transition.

Human activities are largely responsible for global warming [7]. To formulate countermeasures for urban sustainable development, many literatures tried to seek suitable paths through investigating low-carbon related behaviors of individuals or families. They started from the aspect of energy end-user behaviors for prime time [8-10]. Following, dwellers' lifestyles on carbon dioxide emissions were paid attention to. Particularly, Wei et al. [11] investigated residents' lifestyles from the aspects of residence, home energy use, food, education, cultural recreation services, and personal travel. Moloney et al. [12] mentioned the change of sustainable behaviours such as recycling, composting, taking public transport, energy consuming, and water consuming in the transition to low-carbon communities. Baiocchi et al. [13] 
regarded lifestyle-related emissions from the fields of driving, home heating, purchased services, and final goods production. Peters et al. [14] examined household carbonreduction behaviors from four aspects, namely renewable energy, biodiversity, recycling, and green travel. Sun et al. [15] explored residential energy expenditure in different settings including increase in energy pricing, increase in automobile ownership, and improvement of solar energy usage. Simultaneously, scholars [16-18] found that grassroots initiatives helped to realize sustainable consumption through strategic green niches such as using local and recycling materials and reducing material throughput in inhabitation, which were different from mainstream carbonintensive behaviors. In summary, the categories of lowcarbon behaviors that are paid close attention to include the following areas: energy-conserving behaviors [19-21], low-carbon diet [22-24], low-carbon travel [25-27], treatment of waste water [28, 29], waste management [30], and low-carbon production [31-33]. Moreover, most of these studies focused on the change of low-carbon behaviors from traditional behaviors and the reduction of carbon dioxide emission. Considering the importance of the concept of lowcarbon behavior, we offer a definition of low-carbon behavior here. Low-carbon behavior in this paper is referred to human proenvironmental activities or habits that can decrease the impact on ecotope.

Urban dwellers' cognition on low-carbon behaviors influences their specific participations. Many literatures expounded the low-carbon related cognition. A human being's mind includes knowledge, attitude, consciousness, values, affective states, perceptual cognizance and ideas, reasonable thinking, and deep-rooted habits which would greatly affect or reshape individual behaviors [12]. The aspects of knowledge, attitude, and engagement are identified as the most frequently referred dimensions of low-carbon cognition [14]. Individual knowledge means to obtain and apply actually correct understanding related to climate change [34], such as the perception of the concepts of global warming and low-carbon life. Individual attitude means the opinions and standpoints of objective belief related to climate change $[35,36]$, such as the willing of building carbonneutral community and the evaluation of participation in low-carbon practices. Individual engagement means personal contact with the minds or behaviors related to climate change [34], such as paying for energy-saving measures and participating in policy formulation [37]. Meanwhile, scholars explored the relationship between low-carbon cognition and low-carbon behavior [38, 39]. Zhang et al. [40] thought that the external forms of residents' low-carbon cognition incarnated from aspects of transportation, living, and consumptions [40]. Currently, particular emphasis is put on the empirical elaboration of the gap between cognition of and low-carbon behaviors of urban residents $[35,41]$. Residents' cognition of low-carbon behaviors in this paper is referred to personal knowledge, attitude, and engagement on objective existences of low-carbon objects.

The literature review shows that previous studies focus on residents' cognition of and participation in low-carbon behaviors and the correlation between them. Few authors focused on the level of neighborhood residents' participation in low-carbon behaviors or the main field for residents to perform low-carbon behaviors. To make up this omission, we investigated and discussed neighborhood residents' cognition of and participation in low-carbon behaviors in this study. A neighborhood was selected for the test project in Wuhan, which devotes oneself to establish a resourcesaving and environment-friendly society in low-carbon economy development. The sample data were analyzed in IBM SPSS Statistics 21.0 software. And the methods of statistical descriptive analysis, principal component analysis, and multiple linear regression analysis were used. Suggestions for guidance and correction of the approach for neighborhood residents' participation in low-carbon behaviors were proposed further.

\section{Materials and Methods}

2.1. Questionnaire Design. A questionnaire involving 24 questions was designed in a gradual manner to survey neighborhood residents' cognition of and their self-reported level of participation in low-carbon behaviors. The questions 1-3 were used to collect respondents' basic information including their age, education level, and profession. The questions 4-8 were used to obtain their cognition that covered the awareness of global warming, the low-carbon concept and meaning, the low-carbon impaction on their daily lives, energy-saving measures, and government supports.

Questions 9-24 were used to obtain the information of their self-reported level of participation in low-carbon behaviors. Specifically, Question 9 surveyed residents' overall assessment of their own level of participation in low-carbon behaviors. Questions 10-24 collected statistical information of neighborhood residents' concrete situation of participation in various low-carbon behaviors in the form of five Likert scale. All questions were straightforward.

The examination results of performance from neighborhood residents' low-carbon behaviors were divided into five rating levels: always, frequently, occasionally, seldom, and never. In the Likert scale, each issue set out five alternative answers for reviewers on the degree of participation with scores from 5 to 1 ( $5=$ always and $1=$ never). These questions on low-carbon behaviors were designed around the subjects of travelling, power use, consumption, and living habits, based on the above literature review. The factors reflecting respondents' participation in low-carbon behaviors were analyzed with the factor analysis in SPSS tools. Multiple linear regression analysis was used to discuss the relationship between neighborhood residents' low-carbon behavior factors and their overall degree of participation.

2.2. Study Site and Sample. A high-rise residential neighborhood in Wuhan, China was chosen to acknowledge neighborhood residents' cognition of and participation in low-carbon behaviors. The medium-scale and gated neighborhood is near government, hospital, school, shopping center, transport, and other public service infrastructures. Figure 1 shows the situation of the field investigation. 


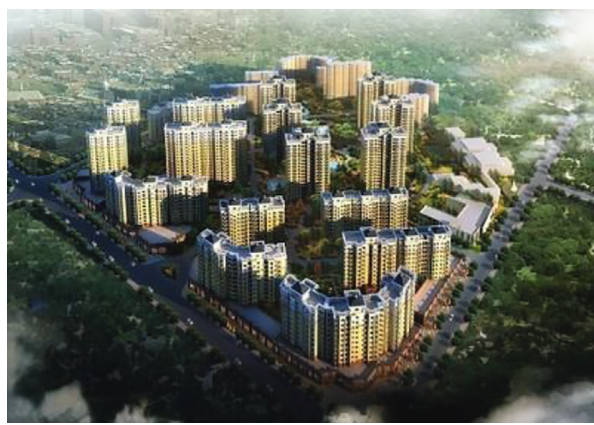

(a)

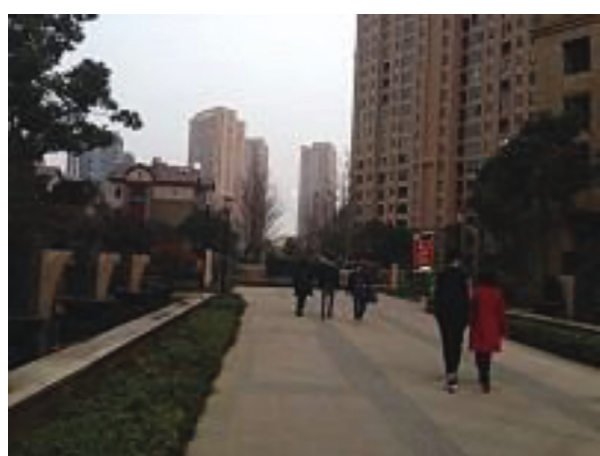

(b)

Figure 1: Situation of field investigation.

TABLE 1: Structure of the respondent populations in the survey.

\begin{tabular}{|c|c|c|c|c|c|}
\hline Item & Subitem & $\%$ & Item & Subitem & $\%$ \\
\hline \multirow{4}{*}{ Age } & $\leq 20$ years & 7.4 & \multirow{4}{*}{ Education level } & Junior high school and below & 6.9 \\
\hline & $21-39$ years & 66.1 & & High school or technical school & 19.6 \\
\hline & $40-59$ years & 20.6 & & College or bachelor degree & 61.4 \\
\hline & $\geq 60$ years & 5.9 & & Graduate degrees & 12.1 \\
\hline \multirow{3}{*}{ Profession } & Enterprise employee & 32.8 & \multirow{3}{*}{ Profession } & Student & 10.6 \\
\hline & Government or institution employees & 15.3 & & Retirees & 5.9 \\
\hline & Self-employed person & 14.8 & & Other & 20.6 \\
\hline
\end{tabular}

The survey was conducted for randomly selected residents who were willing to accept self-administered questionnaires and nonstructured interview. Among the 207 questionnaires distributed, 206 were returned. Excluding 17 ones that have obvious logical contradiction and are not complete, the rest 189 were validated questionnaires, with the effective rate of $91.3 \%$.

The basic information of the valid questionnaires is given below. Table 1 shows the statistics results including ages, educational structures, and occupational categories, in line with the general distribution of neighborhood residents in high-rise building in Wuhan. These samples do not have a great skewed distribution and meet the requirement for further statistics analysis. Among these 189 participants, $7.4 \%$ of residents were 20 years old or younger, $66.1 \%$ were 21-39 years old, $20.6 \%$ were $40-59$ years old, and $5.9 \%$ were 60 years old or older. In the aspect of the academic structure, $6.9 \%$ had middle school degree or below, $19.6 \%$ had high school degree or equivalent technical school degree, $61.4 \%$ had college degree, and $12.1 \%$ had postgraduate degree. In the aspect of respondents' professions, $32.8 \%$ were entrepreneurial employees, $15.3 \%$ were government or institution employees, $14.8 \%$ were self-employed, $10.6 \%$ were students, and the rest $26.5 \%$ were retirees and others.

2.3. Implementation of the Survey. Data were collected using the stratified random sampling method. The investigation was carried out in public places for residents living in the neighborhood and willing to be interviewed voluntarily. Questionnaires were distributed during their weekend breaks. Subjects were randomly selected in the neighborhood.
And all respondents were well informed that their responses would remain confidential and only be used for research purposes. A questionnaire was filled in approximately 15 minutes. The survey process mainly contained self-administered questionnaires and was supplemented by the nonstructured interview method to perfect questionnaires.

2.4. Analytic Strategy. Residents' low-carbon cognition was analyzed using the descriptive statistic method. Neighborhood residents' participation was analyzed with principal component analysis and multiple linear regression analysis. Before carrying out these analyses, it is needed to judge the feasibility of the sample data through reliability test and Bartlett and KMO test.

2.4.1. Reliability Test. Cronbach's $\alpha$ coefficient was used to test the reliability of questionnaires. According to previous report [42], Cronbach's $\alpha$ coefficient $\geq 0.7$ indicates a high-degree reliability, and $<0.35$ indicates low-degree reliability. By redesigning questionnaires and testing the reliability of factors that reflect respondents' self-reported level of participation in low-carbon behaviors, $\alpha$ coefficient of 0.820 was achieved, indicating that the questionnaire design is reasonable and has high internal stability and consistency in each dimension and the measurement is highly reliable.

2.4.2. Bartlett and KMO Test. The appropriation for the initial sampling was measured through the Bartlett spherical test and KMO (Kaiser-Meyer-Olkin) index basing on the factor analysis. When the KMO index is greater than 0.7 , the 


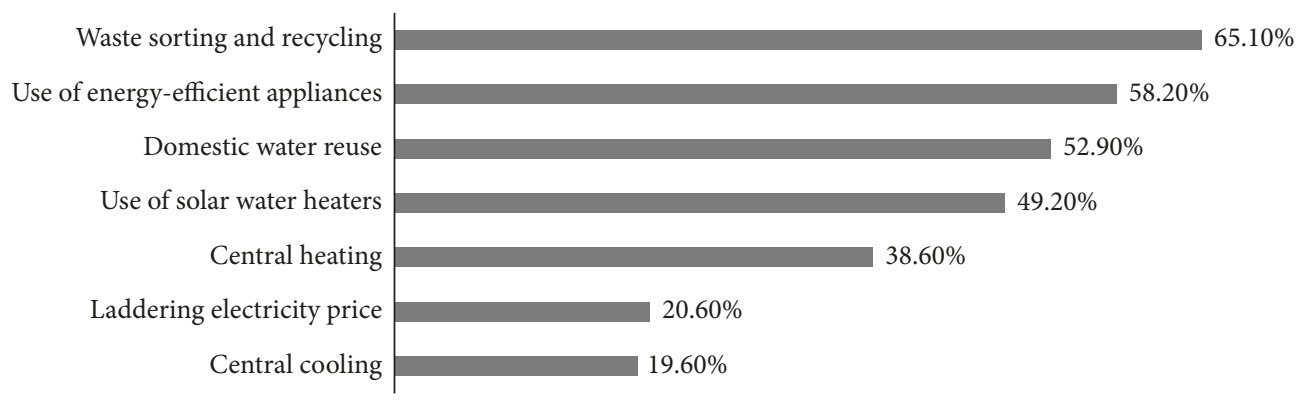

FIGURE 2: Neighborhood residents' preferential selection of domestic low-carbon-related measures.

data are suitable for factor analysis [43]. In this study, the KMO value was 0.820 and the result of the Bartlett spherical test was $657.311 \quad(P<0.001)$. Thus, there were common factors among the designed issues in the questionnaire, and it is suitable to carry out relative exploration with factor analysis.

\section{Results}

3.1. Descriptive Statistic of Low-Carbon Cognition. The analysis results are as follows. In the aspect of global warming, 95.2\% respondents said that they knew and felt the climate change and $4.8 \%$ respondents said that they were unclear about the change. In the aspect of low-carbon concept cognition, $43.4 \%$ respondents were familiar with low-carbon concept and its content, 54.5\% respondents said they knew low-carbon concept without noticing its exact meaning, and $2.1 \%$ never know low-carbon concept. From the interview in the investigative process, it was known that residents gained low-carbon knowledge mainly from television, internet, newspapers, friends, and neighbors. In the aspect of relationship between low-carbon theory and residents' daily lifestyles, $59.8 \%$ residents believed that the two sides were closely related to each other, $37.6 \%$ considered that the two sides were relevant, and $2.6 \%$ thought that the two sides were unrelated. The results show that most respondents had understood and cared about the impact of low-carbon concept on their daily life. Their cognition had consistency.

Figure 2 shows neighborhood residents' preferential selection of domestic low-carbon-related measures. The option of "waste sorting and recycling," "use of energyefficient appliances," and "domestic water reuse" accounted for $65.1 \%, 58.2 \%$, and $52.9 \%$, respectively. Following, the options of "use of solar water heaters" and "central heating" accounted for $49.2 \%$ and $38.6 \%$, respectively. Finally, the option of "laddering electricity price" and "central cooling" accounted for $20.6 \%$ and $19.6 \%$, respectively. The results show that respondents concentrated in areas including waste classification and recycling, energy saving, waste water reuse, and use of clean energy to perform low-carbon related measures.

In the aspect of cognition on urban low-carbon policies, respondents believed that the government would focus on low-carbon transition of communities. Figure 3 shows that respondents overwhelmingly choose "pollution control" and "green space construction" by $67.2 \%$ and $65.6 \%$, respectively, following by $49.2 \%$ of "public transportation" and "propaganda and education of low-carbon lifestyles" each and then $39.7 \%$ of "rewards for low-carbon behaviors." The results indicate that respondents had strong requirement of pollution control such as air pollution control and construction of green space such as parks and greenway. And most residents kept a watchful eye on their circumstance and were appealed to live close to the nature.

In sum, a considerable part of neighborhood residents had sufficient cognition on low-carbon concept. Most of them believed that the low-carbon theory is closely related to their daily life. Majority of respondents were willing to perform low-carbon lifestyles. Additionally, over $40 \%$ residents expected the government to make differences in lowcarbon transition. Neighborhood residents' cognition had no obvious difference.

\subsection{Analysis of Neighborhood Residents'Self-Reported Level of} Participation. Through statistical analysis, it was found that most respondents' overall self-reported level of participation in low-carbon behaviors was intermediate. Among the 189 questionnaires, $5 \%, 21 \%, 65 \%$, and $9 \%$ of residents evaluated their own degree of participation in low-carbon behaviors as "high," "relatively high," "general," and "low," respectively. The factors of low-carbon behaviors with high scores among the observed variables contained four aspects, namely, natural ventilation and lighting, use of energy-saving lamps, taking public transport, and poweroff for unused electrical appliances. It was followed in order by plant cultivation, shopping with carry-on bags or baskets, reuse of waste paper, walking trip, and clothing recycling. What is more, there were big differences in three areas including refusal of one-time service or consumption, waste water reuse, and waste classification and recycling. The average scores of the three were $3.02,2.99$, and 2.95, respectively, which were close to the median value of 3 . Thus, it can be seen that residents had a neutral view to participate in these three low-carbon behaviors. During the interview, some residents expressed their dissatisfaction with imperfect construction of waste classification system, roadway travel, and clothe recycling facilities. Meanwhile, they expressed willingness to accept improved local products with quality and safety assurance and to support the promotion of home water recycling system. 


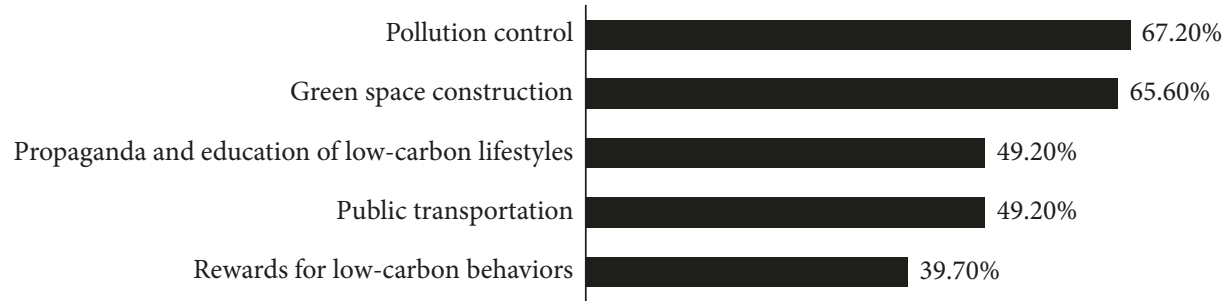

FIGURE 3: Main aspects needed to be supported by the government.

TABLe 2: Principal component extraction and rotation results of each low-carbon behavior variable.

\begin{tabular}{|c|c|c|c|c|c|c|c|c|c|}
\hline \multirow{2}{*}{ Component } & \multicolumn{3}{|c|}{ Initial eigenvalues } & \multicolumn{3}{|c|}{ Extraction sums of squared loadings } & \multicolumn{3}{|c|}{ Rotation sums of squared loadings } \\
\hline & Total & $\%$ of variance & Cumulative \% & Total & $\%$ of variance & Cumulative \% & Total & $\%$ of variance & Cumulative \% \\
\hline 1 & 4.360 & 29.070 & 29.070 & 4.360 & 29.070 & 29.070 & 2.088 & 13.922 & 13.922 \\
\hline 2 & 1.443 & 9.623 & 38.693 & 1.443 & 9.623 & 38.693 & 1.977 & 13.182 & 27.104 \\
\hline 3 & 1.312 & 8.748 & 47.441 & 1.312 & 8.748 & 47.441 & 1.865 & 12.432 & 39.536 \\
\hline 4 & 1.178 & 7.851 & 55.293 & 1.178 & 7.851 & 55.293 & 1.838 & 12.254 & 51.790 \\
\hline 5 & 0.914 & 6.092 & 61.384 & 0.914 & 6.092 & 61.384 & 1.439 & 9.594 & 61.384 \\
\hline 6 & 0.840 & 5.601 & 66.985 & - & - & - & - & - & - \\
\hline 7 & 0.733 & 4.883 & 71.868 & - & - & - & - & - & - \\
\hline 8 & 0.726 & 4.842 & 76.710 & - & - & - & - & - & - \\
\hline 9 & 0.639 & 4.259 & 80.969 & - & - & - & - & - & - \\
\hline 10 & 0.608 & 4.055 & 85.025 & - & - & - & - & - & - \\
\hline 11 & 0.562 & 3.744 & 88.769 & - & - & - & - & - & - \\
\hline 12 & 0.447 & 2.982 & 91.750 & - & - & - & - & - & - \\
\hline 13 & 0.437 & 2.915 & 94.665 & - & - & - & - & - & - \\
\hline 14 & 0.416 & 2.775 & 97.440 & - & - & - & - & - & - \\
\hline 15 & 0.384 & 2.560 & 100.000 & - & - & - & - & - & - \\
\hline
\end{tabular}

3.2.1. Principal Component Analysis. According to the inclusion criteria of characteristic roots greater than 1 [44], the principal component analysis method was used to extract common factors and explain relationship among the observed variables. Table 2 shows the extraction and rotation results among low-carbon behavioral variables. Among them, previous four major elements totally explained $55.293 \%$ of original variables. In order to better reflect the total variance, the component with characteristic value of 0.914 was included into the four main components and used as the 5 th common factors. Then, the cumulative variance contribution rate of these five common factors reached $61.384 \%$. Because it is acceptable for exploratory factor analysis when the contribution rate of cumulative variance is over $50 \%[45,46]$, the cumulative explained variance here was within the acceptable range. The extracted common factors preserved a large amount of information from original data. And the results could be accepted.

The varimax method was selected to orthogonally rotate the variance axis such that load factors of initial common factors were split toward 0 and 1 for summing up explanatory variables among common factors. Through naming high-load variables, five dimensions of indicator variables were confirmed, namely, efficient resource consumption (ERC), recycling habits $(\mathrm{RH})$, home energy conservation (HEC), green travel (GT), and spontaneous environmental behaviors (SEB). Table 3 shows the load matrix and the explained variance and cumulative percentages of each factor after rotation. The factors with load greater than 0.5 were listed among each common factor. Because the observed variables meet the requirements of convergent validity when the loading values of factors are greater than 0.5 [47], 15 observed variable factors in this measurement project were reliable and effective.

3.2.2. Correlation Analysis. The resultant five common factors were set as independent variables, and the neighborhood residents' overall level of participation was set as a dependent variable. Their correlations were analyzed using the Pearson correlation analysis. The Pearson coefficient was used for two-tailed $t$-test. It is apparent from Table 4 that neighborhood residents' overall level of participation was significantly correlated with ERC, RH, and HEC at 0.01 level and with GT at 0.05 level, but not related with SEB.

3.2.3. Multiple Linear Regression Analysis. To further explore the influence extent and the direction of each factor, factors SEB and GT that had weak or no correlation with neighborhood residents' overall degree of participation were excluded. ERC, RH, and HEC were set as three independent variables which had high correlation with neighborhood residents' overall participation level. The overall degree of residents' participation was set as dependent variable. The correlation between independent variables and the dependent variable was analyzed using the stepwise regression method. Table 5 shows the regression coefficients of constants and variables with significant level less than 0.01 . 
TABLE 3: Loading matrix and cumulative explained variance after rotation.

\begin{tabular}{|c|c|c|c|}
\hline Factors & Factor loading & Explained variance $(\%)$ & Cumulative explained variance (\%) \\
\hline Efficient resource consumption (ERC) & & 13.922 & 13.922 \\
\hline Waste water reuse & 0.776 & & \\
\hline $\begin{array}{l}\text { Use of water-saving devices (such as water-efficient } \\
\text { closestools and showers) }\end{array}$ & 0.635 & & \\
\hline Reuse of waste paper & 0.558 & & \\
\hline Support of local products & 0.653 & & \\
\hline Recycling habits $(\mathrm{RH})$ & & 13.182 & 27.104 \\
\hline Clothing recycling & 0.682 & & \\
\hline Refusal of one-time services or consumptions & 0.532 & & \\
\hline Waste classification and recycling & 0.747 & & \\
\hline Home energy conservation (HEC) & & 12.432 & 39.536 \\
\hline Use of energy-saving lamps & 0.735 & & \\
\hline Natural ventilation and lighting & 0.780 & & \\
\hline Poweroff for unused household appliances & 0.619 & & \\
\hline Green travel $(\mathrm{GT})$ & & 12.254 & 51.790 \\
\hline Taking public transport & 0.771 & & \\
\hline Walking trip & 0.732 & & \\
\hline Transportation by bikes or electromobiles & 0.569 & & \\
\hline Spontaneous environmental behaviors (SEB) & & 9.594 & 61.384 \\
\hline Shopping with carry-on bags or baskets & 0.592 & & \\
\hline Plant cultivation & 0.786 & & \\
\hline
\end{tabular}

TABLE 4: Correlation between factors of low-carbon behaviors and the overall degree of participation.

\begin{tabular}{lccc}
\hline Factors & $\begin{array}{c}\text { Overall degree of participation in low-carbon behaviors } \\
\text { Pearson } \\
\text { correlation }\end{array}$ & $\begin{array}{c}\text { Significance } \\
\text { (2-tailed) }\end{array}$ & $\begin{array}{c}\text { Significance } \\
\text { level }\end{array}$ \\
\hline ERC & 0.207 & 0.004 & $0.01^{* *}$ \\
RH & 0.205 & 0.005 & $0.01^{* *}$ \\
HEC & 0.300 & 0.000 & $0.01^{* *}$ \\
GT & 0.147 & 0.044 & $0.05^{*}$ \\
SEB & 0.042 & 0.562 & Uncorrelated \\
\hline
\end{tabular}

Note: ${ }^{* *} p<0.01 ;{ }^{*} p<0.05$.

The results show that each regression equation possessed statistical significance at 0.001 level. And these regression coefficients in the three models have good statistical significance. Through comparing the standardized coefficients of independent variables in models, it can be seen that factors ERC, RH, and HEC have strong influences on the overall degree of residents' participation in low-carbon behaviors. Multicollinearity diagnostic results show that the tolerance and variance inflation factor (VIF) of each variable is 1 , indicating no collinearity hypothesis among independent variables in each equation. And the colinear hypothesis was refused. Therefore, the multiple linear regression equation of the degree of neighborhood residents' participation in low-carbon behaviors can be expressed as

The overall degree of participation in low-carbon behaviors

$$
=3.138+0.263 \times \mathrm{HEC}+0.181 \times \mathrm{ERC}+0.180 \times \mathrm{RH} \text {. }
$$

In sum, ERC, RH, HEC, GT, and SEB were the five principal factors related to respondents' level of participation in low-carbon behaviors. Excluding SEB which was not correlated with neighborhood residents' level of participation, the rest of the components that had significant effect were HEC, ERC, RH, and GT in order. These four had linear relationships with respondents' overall level of participation. Specifically, HEC had a significant positive impact on neighborhood residents' overall level of participation in low-carbon behaviors. ERC presented a high positive correlation with neighborhood residents' degree of participation. Meanwhile most residents expressed their willingness to buy local products with quality and safety assurance. $\mathrm{RH}$ largely contributed to improve neighborhood residents' degree of participation. GT was not obviously correlated with residents' level of participation.

\section{Discussion and Suggestions}

The following points could be drawn from the above results.

(1) Neighborhood residents have high cognition on lowcarbon theory but intermediate-level participation in low-carbon behaviors through their self-reported survey, which is similar to the results which were generally identified from the previous studies [48, 49]. Moreover, people participated in low-carbon behaviors with certain motivation especially related to economic interest. But in the fields such as being close to the nature and looking after plants, neighborhood residents spontaneously perform low-carbon related behaviors.

(2) The results in this paper revealed people's level of participation in low-carbon behaviors at the neighborhood scale, while many previous literatures emphasized on the impact of individual low-carbon behavior change $[12,18,50]$. It was discovered that most respondents cared about the low-carbon impact on their daily lives and concentrated their participation in low-carbon behaviors from traditional 
TABLE 5: Coefficient analysis of regression models.

\begin{tabular}{|c|c|c|c|c|c|c|c|c|}
\hline \multirow{2}{*}{\multicolumn{2}{|c|}{ Model }} & \multicolumn{2}{|c|}{$\begin{array}{l}\text { Unstandardized } \\
\text { coefficients }\end{array}$} & \multirow{2}{*}{$\begin{array}{l}\text { Standardized coefficients } \\
\text { Beta }\end{array}$} & \multirow[t]{2}{*}{$t$} & \multirow[t]{2}{*}{ Significance } & \multicolumn{2}{|c|}{ Collinearity statistics } \\
\hline & & $\mathrm{B}$ & Stdandard error & & & & Tolerance & VIF \\
\hline \multirow{2}{*}{1} & Constant & 3.138 & 0.061 & - & 51.445 & 0.000 & - & - \\
\hline & HEC & 0.263 & 0.061 & 0.300 & 4.294 & 0.000 & 1.000 & 1.000 \\
\hline \multirow{3}{*}{2} & Constant & 3.138 & 0.060 & - & 52.556 & 0.000 & - & - \\
\hline & HEC & 0.263 & 0.060 & 0.300 & 4.387 & 0.000 & 1.000 & 1.000 \\
\hline & ERC & 0.181 & 0.060 & 0.207 & 3.027 & 0.003 & 1.000 & 1.000 \\
\hline \multirow{4}{*}{3} & Constant & 3.138 & 0.058 & - & 53.734 & 0.000 & - & - \\
\hline & HEC & 0.263 & 0.059 & 0.300 & 4.485 & 0.000 & 1.000 & 1.000 \\
\hline & ERC & 0.181 & 0.059 & 0.207 & 3.095 & 0.002 & 1.000 & 1.000 \\
\hline & $\mathrm{RH}$ & 0.180 & 0.059 & 0.205 & 3.071 & 0.002 & 1.000 & 1.000 \\
\hline
\end{tabular}

measures of domestic energy or resource conservation. Furthermore, they even equated energy-saving or resource-saving measures with low-carbon measures, though the equating makes the universal and abundant low-carbon concept become narrow and hinders low-carbon behaviors to be launched in a variety of forms.

(3) In spite of considerable advances in residents' recognition and implementation of low-carbon related behaviors, there is still space for improvement. For example, most neighborhood residents would like to donate and recycle used clothing but were always hindered by the absence of standardized and effective channels or systems. Meanwhile, quite a number of respondents emphasized particularly on increasing waste separation facilities and improving supervision mechanisms and agreed to abstain and resist various disposable consumer products such as disposable chopsticks, toiletries, and plastic bags, though some expressed their difficulties to do so in their daily lives. Furthermore, due to the restrictions of haze, air pollution, or travel distance, few people adopted pedestrian way to travel. Especially, people who were far away from the subway or bus stops preferred to drive cars. However, most residents expressed their willingness to participate in low-carbon travel if their convenient travel was offered. In addition, though young male residents generally refused to carry reusable bags, some residents have gradually formed the habit of carrying shopping bags after the promulgation of limited use of plastic. In short, neighborhood residents' level of participation is improving.

To enhance the overall level of neighborhood residents' participation in low-carbon behaviors and to meet the demand of low-carbon development, the following are recommended:

(1) A typical model of low-carbon survival pattern should be set up for neighborhood residents to learn and refer to. The organization of low-carbon activities related to clothing, food, housing, and behaviors would effectively promote personal involvement in low-carbon behaviors. In addition, appropriate material rewards and spiritual encouragements would encourage individuals to lead a low-carbon lifestyle and help improve residents' enthusiasm in participation.

(2) Neighborhood residents' awareness of low-carbon theory needs to be reinforced. Low-carbon cognition can offer an enduring base for residents to participate in low-carbon behaviors. Neighborhood residents' understanding about low-carbon concept can be enhanced through lectures and cultural and product exhibitions. Low-carbon concept can constantly penetrate toward residents' living. Therefore, individual living and consumption habits could be reshaped gradually for suitable low-carbon pattern.

(3) The employment of sharing mechanism of responsibility will be conducive to the construction of harmonious and healthy relationships among neighborhoods. Good neighborhood relations help increase neighborhood residents' interaction and participation initiatives in their daily lives. The implementation of burden sharing helps gradually achieve the low-carbon transition of residents' behaviors by performing and undertaking the responsibility of low-carbon construction.

(4) The use of high-tech innovation technology contributes to residents' innovative behaviors in urban low-carbon transition. Especially the employment of new energy technology, advanced sanitation technology, and high-performance technology could provide support for low-carbon transition of neighborhoods. So the encouragement of lowcarbon innovation and the improvement of energy efficiency are inevitable choices to build low-carbon neighborhoods.

(5) Matching mechanism and policy and public service infrastructures contribute to individual participation in low-carbon behaviors. The formulation and revision of low-carbon related regulations such as domestic energy-saving ordinances and detailed rules could regulate residents' consuming behaviors and provide deep pulling power for low-carbon transition in neighborhoods. Simultaneously, mature physical infrastructures such as public transportation, 
urban greenways, parkland, squares, and sanitation facilities offer convenience for residents to participate in low-carbon behaviors.

\section{Conclusions}

Personal energy consumption takes up a crucial part of carbon dioxide emissions. Residents' cognition of and participation in low-carbon behaviors have significant roles in the low-carbon transformation in neighborhoods for coping with the climate change. Basing on a questionnaire survey, individual cognition of and participation in lowcarbon behaviors were analyzed. Several findings were achieved through an investigation in Wuhan, China. First, most respondents believed the low-carbon impact on their daily lives and participated in low-carbon behaviors from traditional aspects of domestic energy or resource conservation. Second, many interviewees tended to participate in low-carbon behaviors with the motivation of economic interest. When the behaviors are related to the aspects of energy, resource, or consumption that are directly related to personal monetary benefits, respondents showed high level of participation. Finally, they rarely participate in public low-carbon behaviors such as planting trees or other lowcarbon behaviors that are done through cooperation or interchange among residents, although there are big potential powers for residents to implement this kind of lowcarbon behaviors. Therefore, neighborhood residents' participation in low-carbon behaviors is still at exploratory stage.

These findings have a large amount of implications for the implementation of low-carbon development. Recently, a number of projects have been launched for sewage treatment, waste recycling, and new energy exploration. But the cognition of low-carbon knowledge is still recognized to be the pushing hand for further encouraging neighborhood residents' participation in low-carbon behaviors. In addition, policies, standard, and rules need to be made for the guarantee of their performance.

Though this explorative study can help us to acknowledge neighborhood residents' degree of participation in lowcarbon behaviors and cognition status, there are still some limitations as follow. (1) The relevance of neighborhood residents' cognition or the sociodemographic variables with their participation in low-carbon behaviors, and the relationship between neighborhood residents' low-carbon cognition and their participation in low-carbon behaviors are worth for further study. (2) The factors affecting household energy consumption behaviors and the basic conditions for individual participation in low-carbon lifestyles are worth to be discussed further. (3) Questionnaires need to be designed more comprehensively and to cover other public low-carbon behaviors. (4) There may appear the tendency of intermediate value choice which leads to some bias and lacking property differences because the social investigation is basing on neighborhood residents' self-reported data-related low-carbon issues. Therefore, further research is needed to adopt other methods or tools to collect data and reduce subjectivity.

\section{Conflicts of Interest}

The authors declare that they have no conflicts of interest.

\section{Acknowledgments}

This work was supported by the Key Project of National Science and Technology Support Program for the Twelfth Five-Year Plan of China, "Research and Demonstration of Planning and Construction Monitoring Technology in Green Ecological Village” (2014BAL04B03-3).

\section{References}

[1] Y. Chen, "Suggestions of speeding up the development of new pattern urbanization within Sichuan province," Reform of Economic System, vol. 6, pp. 133-137, 2010.

[2] J. E. Fernández, "Resource consumption of new urban construction in China," Journal of Industrial Ecology, vol. 11, no. 2, pp. 99-115, 2007.

[3] NBSC National Bureau of Statistics of China, China Statistical Yearbook, China Statistics Press, Beijing, China, 2016.

[4] X. Li, "Low-carbon ecology leading a new direction of urban development," Environmental Protection \& Recycling Economy, vol. 6, pp. 4-6, 2010.

[5] D. Zeng and X. Wang, "Comparative study of relationship between carbon emission and medium-term urbanization in different countries," Journal of Chongqing University, vol. 21, no. 1, pp. 46-50, 2015.

[6] L. Yan and J. B. Zhao, "A brief discussion about construction of low-carbon and energy-saving ecological communitya case study of Yilongwan community in Changzhi city," Advanced Materials Research, vol. 689, pp. 524-527, 2013.

[7] J. T. Houghton, Y. Ding, D. J. Griggs et al., Climate Change 2001: The Scientific Basis, Cambridge University Press, New York, NY, USA, 2001.

[8] F. Bartiaux, "A socio-anthropological approach to energyrelated behaviours and innovations at the household level," in Proceedings of ECEEE 2003 Summer Study-Time to Turn Down Energy Demand, pp. 1239-1250, Saint-Raphaël, France, June 2003.

[9] Z. H. Feng, L. L. Zou, and Y. M. Wei, "The impact of household consumption on energy use and $\mathrm{CO}_{2}$ emissions in China," Energy, vol. 36, no. 1, pp. 656-670, 2010.

[10] B. C. O'Neill and B. S. Chen, "Demographic determinants of household energy use in the United States," Population \& Development Review, vol. 28, no. 10, pp. 53-88, 2002.

[11] Y. M. Wei, L. C. Liu, Y. Fan, and G. Wu, "The impact of lifestyle on energy use and $\mathrm{CO}_{2}$, emission: an empirical analysis of china's residents," Energy Policy, vol. 35, no. 1, pp. 247-257, 2007.

[12] S. Moloney, R. E. Horne, and J. Fien, "Transitioning to low carbon communities-from behaviour change to systemic change: lessons from Australia," Energy Policy, vol. 38, no. 12, pp. 7614-7623, 2010.

[13] G. Baiocchi, J. Minx, and K. Hubacek, "The impact of social factors and consumer behavior on carbon dioxide emissions in the United Kingdom," Journal of Industrial Ecology, vol. 14, no. 1 , pp. 50-72, 2010.

[14] M. Peters, S. Fudge, and P. Sinclair, "Mobilising community action towards a low-carbon future: opportunities and challenges for local government in the UK," Energy Policy, vol. 38, no. 12, pp. 7596-7603, 2010. 
[15] C. Sun, X. Ouyang, H. Cai, Z. Luo, and A. Li, "Household pathway selection of energy consumption during urbanization process in China," Energy Conversion \& Management, vol. 84, pp. 295-304, 2014.

[16] F. Biddau, A. Armenti, and P. F. Cottone, "Socio-psychological aspects of grassroots participation in the transition movement: an Italian case study," Journal of Social and Political Psychology, vol. 4, no. 1, pp. 142-165, 2016.

[17] G. Feola and R. Nunes, "Success and failure of grassroots innovations for addressing climate change: the case of the transition movement," Global Environmental Change, vol. 24, no. 1, pp. 232-250, 2013.

[18] P. Jiang, Y. Chen, B. Xu, W. Dong, and E. Kennedy, "Building low carbon communities in China: the role of individual's behaviour change and engagement," Energy Policy, vol. 60, pp. 611-620, 2013.

[19] H. Arikawa, Y. Cao, and S. Matsumoto, "Attitudes toward nuclear power and energy-saving behavior among Japanese households," Energy Research \& Social Science, vol. 2, pp. 12-20, 2014.

[20] H. B. Enzler, A. Diekmann, and R. Meyer, "Subjective discount rates in the general population and their predictive power for energy saving behavior," Energy Policy, vol. 65, no. 2, pp. 524-540, 2014.

[21] M. Hamamoto, "Energy-saving behavior and marginal abatement cost for household $\mathrm{CO}_{2}$ emissions," Energy Policy, vol. 63, no. 4, pp. 809-813, 2013.

[22] S. Brodt, G. Feenstra, and T. Tomich, "The low-carbon diet initiative: reducing energy use and greenhouse gas emissions in the food system using life cycle assessment," in Proceedings of Summary of a Symposium on Critical Issues and Research Methods, pp. 8-10, UC Davis Agricultural Sustainability Institute, Davis, CA, USA, October 2007.

[23] D. A. Cleveland, C. N. Radka, N. M. Müller et al., "Effect of localizing fruit and vegetable consumption on greenhouse gas emissions and nutrition, Santa Barbara County," Environmental Science \& Technology, vol. 45, no. 10, pp. 4555-4562, 2011.

[24] C. Liang and X. Li, "Behavior intention of low-carbon diet: a perspective of theory of planned behavior," in Proceedings of International Conference on Social Science, Education Management and Sport Education, Beijing, China, April 2015.

[25] N. W. Kuo and Y. Y. Dai, "Predicting low-carbon travel behavior: a modified theory of planned behavior model from Taiwan," Brain Research, vol. 48, pp. 147-156, 2015.

[26] J. Meng, Y. Mu, H. Jia, J. Wu, X. Yu, and B. Qu, "Dynamic frequency response from electric vehicles considering travelling behavior in the Great Britain power system," Applied Energy, vol. 162, no. 2, pp. 966-979, 2016.

[27] E. Shafiei, B. Davidsdottir, J. Leaver, H. Stefansson, and E. I. Asgeirsson, "Potential impact of transition to a lowcarbon transport system in Iceland," Energy Policy, vol. 69, no. 2, pp. 127-142, 2014.

[28] T. L. Qin, D. H. Yan, G. Wang, and J. Yin, "Water demand forecast in the Baiyangdian Basin with the extensive and lowcarbon economic modes," Journal of Applied Mathematics, vol. 4, pp. 1-10, 2014.

[29] D. H. Yan, T. L. Qin, W. H. Xiao, and D. X. Li, "Study on the model of water resources rational deployment for the lowcarbon development mode," Journal of Hydraulic Engineering, vol. 43, no. 5, pp. 586-593, 2012.

[30] E. Papargyropoulou, S. Colenbrander, A. H. Sudmant, A. Gouldson, and L. C. Tin, "The economic case for low carbon waste management in rapidly growing cities in the developing world: the case of Palembang, Indonesia," Journal of Environmental Management, vol. 163, pp. 11-19, 2015.

[31] S. Qu, X. Shi, and G. Hua, "Decision model for the subsides to low-carbon production by the government under the emission trading scheme," LISS, vol. 46, no. 6, pp. 907-917, 2013.

[32] X. Shi and H. Meier, "Carbon emission assessment to support planning and operation of low-carbon production systems," Procedia CIRP, vol. 3, no. 1, pp. 329-334, 2012.

[33] P. Wu and Y. Feng, "Identification of non-value adding activities in precast concrete production to achieve low-carbon production," Architectural Science Review, vol. 57, no. 2, pp. 105-113, 2014.

[34] J. Wolf and S. C. Moser, "Individual understandings, perceptions, and engagement with climate change: insights from in-depth studies across the world," Wiley Interdisciplinary Reviews Climate Change, vol. 2, no. 4, pp. 547-569, 2011.

[35] Y. Bai and Y. Liu, “An exploration of residents' low-carbon awareness and behavior in Tianjin, China," Energy Policy, vol. 61, pp. 1261-1270, 2013.

[36] G. Bohner and N. Dickel, "Attitudes and attitude change," Annual Review of Psychology, vol. 62, no. 1, pp. 391-417, 2011.

[37] S. O'Neill and S. Nicholson-Cole, “"Fear won't do it”: promoting positive engagement with climate change through visual and iconic representations," Science Communication, vol. 30, pp. 355-379, 2009.

[38] L. Zhu, F. Lin, and H. Lu, "Status quo of residents' low-carbon life in Minhang district: survey and enlightenment," Environmental Science \& Technology, vol. 35, no. 1, pp. 195-200, 2012.

[39] J. W. Jung and S. Y. Cho, "The effect of cognition degree of green life on green consumer behavior," Journal of Environmental Science International, vol. 23, no. 8, pp. 1455-1462, 2014.

[40] Y. P. Zhang, "Low-carbon economy and low-carbon life," Sino-Global Energy, vol. 14, no. 4, pp. 12-15, 2009.

[41] Y. Liu and Y. Bai, “An exploration of firms' awareness and behavior of developing circular economy: an empirical research in China," Resources Conservation \& Recycling, vol. 87, pp. 145-152, 2014.

[42] J. P. Guielford, Fundamental Statics in Psychology and Education, Mc Graw-Hill, New York, NY, USA, 1965.

[43] K. Backhaus, B. Erichson, W. Plinke, X. Y. Wang, and W. Rolf, Multivariate Statistical Analysis, Gezhi Press \& Shanghai People's Publishing House, Shanghai, China, 2nd edition, 2017.

[44] Z. M. Du, Sample Survey and Statistical Applications are with SPSS, pp. 689-697, Publishing House of Electronics Industry, Beijing, China, 2010.

[45] D. N. Lawley and A. E. Maxwell, Factor Analysis as a Statistical Method, Butterworth, London, UK, 1971.

[46] J. Stevens, Applied Multivariate Statistics for the Social Sciences, pp. 45-99, Lawrence Erlbaum Associates, Mahwah, NJ, USA, 1986.

[47] J. F. Hair, W. C. Black, B. J. Babin, R. E. Anderson, and R. L. Tatham, Multivariate Data Analysis, Prentice Hall, Upper Saddle River, NJ, USA, 7th edition, 2010.

[48] H. Jiang and L. Zhang, "Research on low-carbon community based on individual behavior change," Science and Technology Management Research, vol. 5, pp. 202-205, 2013.

[49] C. Wu and W. Zhang, "An empirical study of low-carbon cognitive, attitudes and behaviors," Technoeconomics \& Management Research, vol. 7, pp. 123-128, 2013.

[50] S. Capstick, I. Lorenzoni, A. Corner, and L. Whitmarsh, "Prospects for radical emissions reduction through behavior and lifestyle change," Carbon Management, vol. 5, no. 4, pp. 429-445, 2014. 


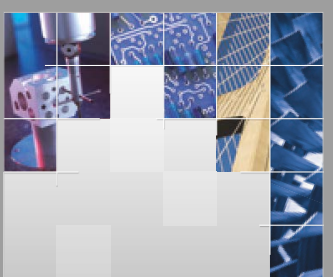

\section{Enfincering}
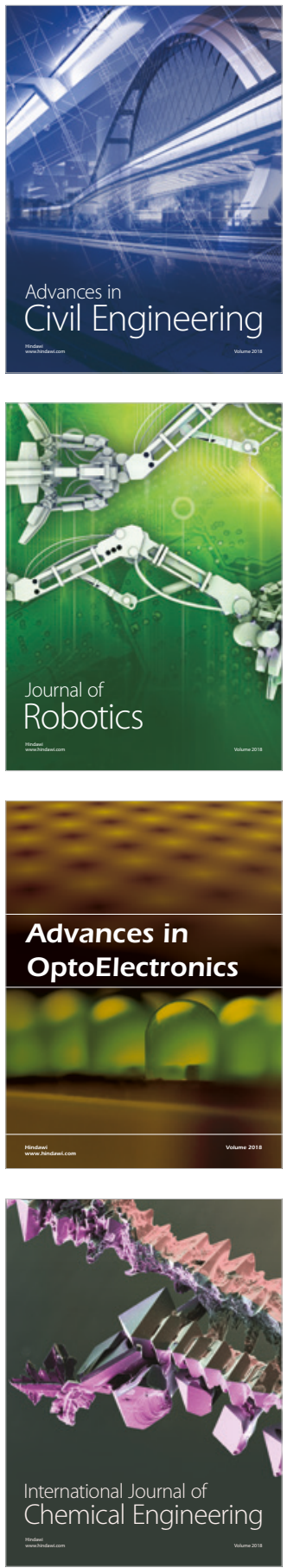

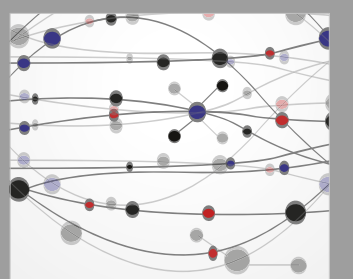

\section{Rotating \\ Machinery}

The Scientific World Journal

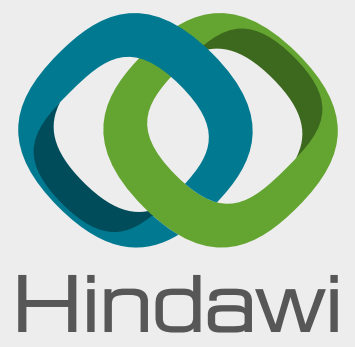

Submit your manuscripts at

www.hindawi.com
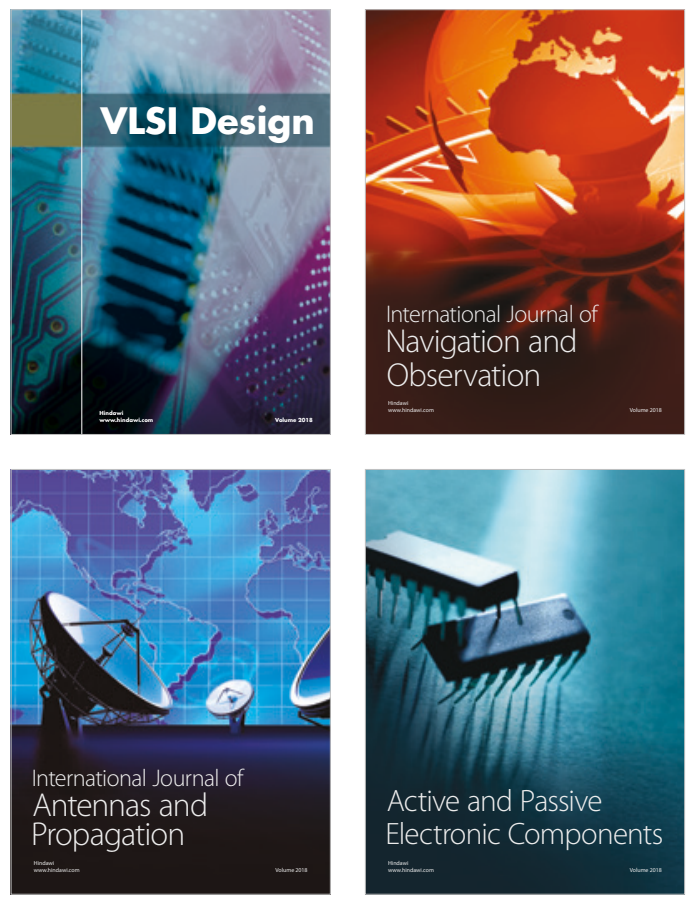
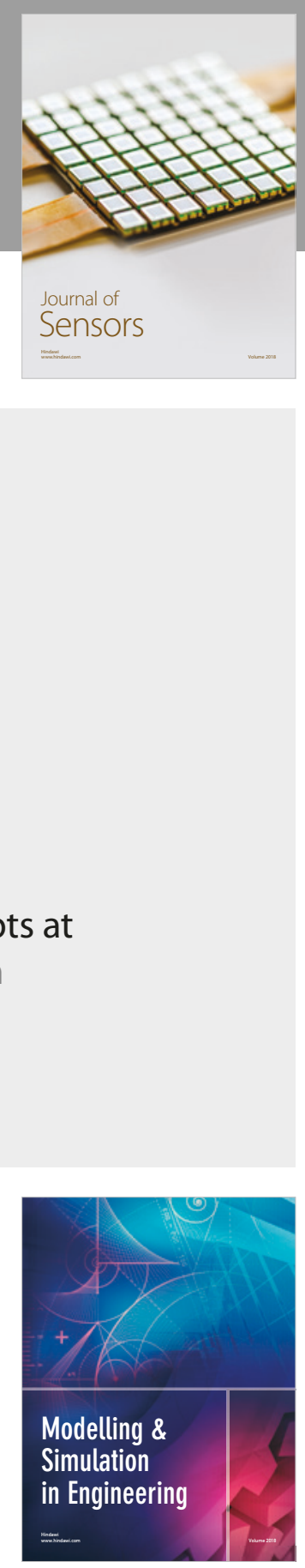

\section{Advances \\ Multimedia}
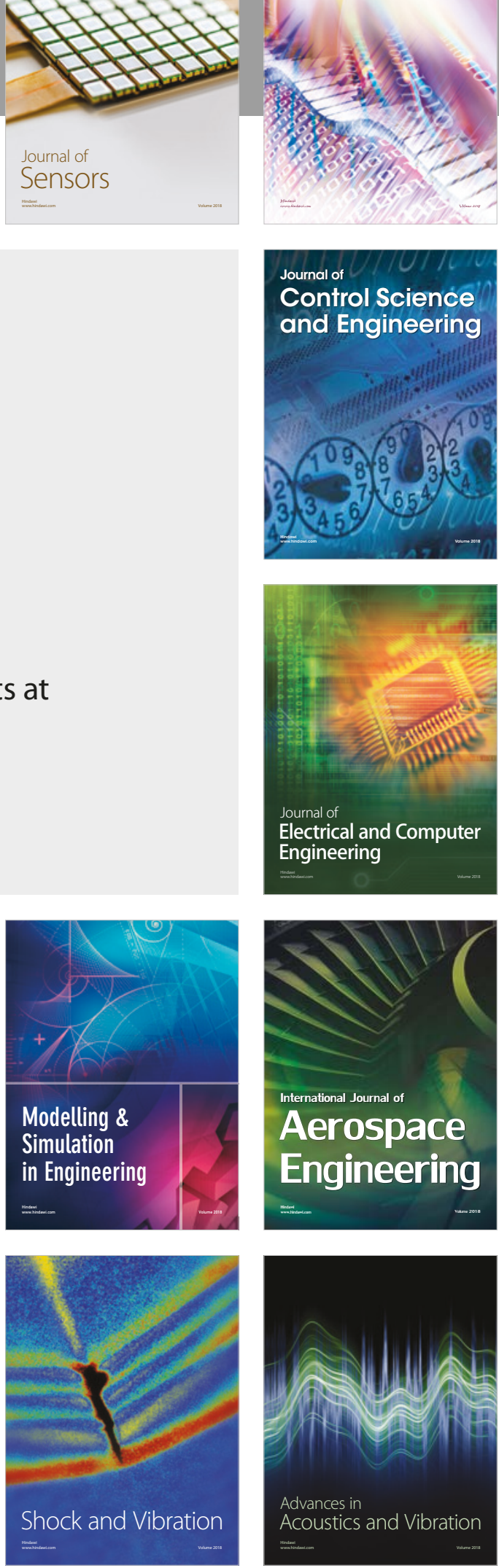